\title{
Responsividade democrática na democracia brasileira
}

\author{
João Henrique Pederiva \\ Universidade de Brasília (UnB)
}

Patrícia Lima Martins Pederiva

Universidade de Brasília (UnB)

\begin{abstract}
A mensuração de quanto é necessário para alterar a realidade social - conexão orçamentária - e a avaliação das correspondências entre agendas de escolhas efetuadas pelos agentes públicos e agendas de preferências populares - responsividade democrática permitem inferências sobre a qualidade dos sistemas políticos democráticos e a incidência de riscos regulatórios. O teste empírico desse modelo analítico utiliza dados de gastos federais brasileiros, registros de atividades no Plenário do Senado Federal e indicações do principal problema nacional em pesquisas de opinião pública efetuadas pelo Latinobarômetro. Os resultados confirmam o maior risco regulatório associado à dívida pública e previdência social, além do descompasso entre as agendas da população e dos agentes públicos legislativos e executivos. Tal descompasso indica a necessidade de incentivar, mediante a regulação das prestações de contas governamentais, o maior alinhamento das expectativas reveladas pelas agendas de preferências dos diversos integrantes do sistema político brasileiro.
\end{abstract}

Palavras-chave: democracia, accountability, acesso à informação, transparência governamental, controle social

[Artigo recebido em 26 de maio de 2015. Aprovado em 8 de março de 2016.] 


\section{Responsividad democrática en la democracia brasileña}

La medida de lo necesario para cambiar la realidad social - conexión presupuestaria-y de la correspondencia entre agendas de decisiones tomadas por los agentes públicos y agendas de las preferencias populares - responsividad democrática - permite inferencias acerca de la calidad de los sistemas políticos democráticos y la incidencia de los riesgos regulatorios. La prueba empírica de este modelo analítico utiliza datos de gastos federales brasileños, registros de actividades en el Senado e indicaciones populares del principales problema nacional en encuestas de opinión pública realizadas por Latinobarómetro. Los resultados confirman el mayor riesgo regulatorio asociado con la deuda pública y la seguridad social, además de la falta de coincidencia entre las agendas de la población y de los funcionarios legislativos y ejecutivos. Ese desajuste indica la necesidad de ajuste de las prestaciones de cuentas gubernamentales, buscando mejor alineamiento de las expectativas reveladas en las agendas de las preferencias de los integrantes del sistema político brasileño.

Palabras clave: democracia, accountability, acceso a la información, transparencia gubernamental, control social

\section{Democratic responsiveness in Brazilian democracy}

The measurement of how much is necessary to change the social reality - budgetary connection - and the assessment of the correlation between agendas of choices done by public agents and the people - democratic responsiveness - enable us to make inferences about the quality of democratic political systems and the incidence of regulatory risks. The empirical test of that analytical model uses data related to Brazilian federal expenditures, the records of activities in the plenary of the Federal Senate and indications of the main national problem in public opinion survey conducted by the Latinobarometro Corporation. The results confirm a higher regulatory risk associated with debt and social welfare. In addition, it shows a mismatch between the agendas of the population and the agendas of the legislative and executive public agents. Such disparity indicates the need to encourage further alignment of the expectations revealed in the preferences agendas of the partnerships of the Brazilian political system by regulation of the governmental accountability.

Keywords: democracy, accountability, access to information, government transparency, social control 


\section{Introdução}

As abordagens pragmáticas e empíricas dos vínculos entre informação e democracia têm merecido cada vez mais atenção de pesquisadores e da opinião pública (MATTESSICH, 1995; O'DWYER, 2005). A responsabilidade pelas prestações de contas governamentais (accountability) determina que, nas democracias, o cidadão delegante tenha direito às informações que Ihe permitam debater publicamente os temas de interesse coletivo com os demais cidadãos e respectivos representantes delegados (Governmental Accounting StANDARds BoARD, 2002, § 18; O'DWYer, 2005; SHAPIRO, 2006).

Em sua teoria democrática, Downs (1957) enfatiza a racionalidade informacional que preside as relações entre cidadãos e governantes e afirma a necessidade de focalização da atenção pública em áreas decisórias. Tal focalização ocorre por intermédio de quatro tipos ideais de provedores de informações para os cidadãos não especialistas: governos, políticos, grupos de interesses e profissionais em coleta, produção e divulgação (mídia). O uso dessas informações subsidiadas, isto é, disponibilizadas sem custo adicional específico para os cidadãos, eleva o risco de perda do controle social sobre os critérios empregados na elaboração e disseminação dessas informações, uma vez que os governos são parte interessada na relação de accountability.

The vast majority of these [governmental] data are shaped solely by the necessities of administration and are not political in nature. Nevertheless, they provide important evidence for citizens who are making political decisions, because they tell these citizens what policies the government is carrying out. Since any changes in policy must be especially well-girded with instructions to those affected, a great deal of this information is focused upon differential areas of action (DowNS, 1957, p. 227).

De fato, a análise dos relacionamentos entre regulação das prestações de informações públicas e qualidade das democracias representativas permite a identificação de potenciais pontos de carências regulatórias e sugere aperfeiçoamentos da ordem jurídica que reduzam os custos transacionais da representação política e melhorem a qualidade da democracia representativa (PEDER IVA; RenNó, 2015; SOROKA; WLEZIEN, 2010).

O principal argumento ora examinado é de que a regulação da accountability afeta o mercado informacional, concernente à percepção e à avaliação das políticas públicas prestadas, com efeitos diretos e imediatos na qualidade do controle social e da democracia em geral. Assim, situações de maior descompasso entre as agendas populares, de elites e de prestações públicas sugerem a necessidade de 
maior atenção legiferante, dada a elevação dos riscos de oportunismo decorrentes da menor visibilidade temática para o controle social dos interessados nos custos e nos efeitos da representação.

Pragmaticamente, a aferição da qualidade dessa regulação passa pela identificação continuada e objetiva das agendas de preferências dos públicos contemplados de modo sistemático pelas escolhas públicas (O'DWYER, 2005). Empiricamente, o presente trabalho usa a conexão orçamentária e a responsividade democrática como construtos teóricos que amparam a mensuração da correspondência entre as agendas das políticas de gastos e das preferências das elites parlamentares federais e da população na democracia brasileira.

A conexão orçamentária traduz as atividades políticas em informações de desempenho comparáveis no tempo e entre diferentes modalidades de representação (PEDERIVA; RENNó, 2015). Desse modo, a conexão orçamentária identifica as expectativas coletivas, quanto aos meios empregados e aos resultados pretendidos e alcançados por tais atividades.

Tal conexão responde objetiva e sucintamente à pergunta sobre o quanto é necessário para manter ou alterar a realidade presente, e permite a realização de inferências acerca do encaminhamento observado pelas ações governamentais (PEDERIVA; RENNó, 2015). A definição da conexão orçamentária abrange as dimensões qualitativas e quantitativas das variáveis, mediante definição de critérios para inclusão ou exclusão em categorias analíticas e métricas numéricas de natureza financeira, física e relacional, como percentuais ou proporções.

A conexão orçamentária está associada a práticas e instituições que podem reduzir ou aumentar incertezas. Em sistemas políticos democráticos, os incentivos do sistema político deveriam alinhar escolhas coletivas e políticas públicas às demandas populares majoritárias. Assim, menores graus de convergência entre tais agendas refletem incentivos regulatórios não democráticos e identificam níveis mais reduzidos de democracia, além de maiores graus de incerteza sobre a sustentabilidade das escolhas públicas associadas aos processos decisórios nas arenas de representação política (SOROKA; WLEZIEN, 2010).

Desse modo, diferentes graus de correspondência entre essas agendas também indicam as áreas ou os temas em que há mais necessidade de atenção regulatória, sob risco do aumento da incidência de oportunismos decisórios dos agentes públicos em prejuízo da representação substantiva dos principais, isto é, a população em geral ou, pelo menos, os públicos majoritários (SUNSTEIN, 2001; PITKIN, 1967).

O conceito de responsividade democrática ora empregado comporta várias facetas. Por exemplo, Soroka e Wlezien (2010) usam esse construto para medir a qualidade democrática das instituições políticas. Contudo, eles não exploram o seu potencial ético e normativo. 
Considerando os ideais de justiça social, "La capacidad ético-responsiva requiere de la sabiduría práctica que considere la singularidad del caso, pero pasando por la prueba de la norma [...]", sob pena de o relativismo moral descambar no arbítrio de minorias ou maiorias (GoNZÁLEZ, 2010, p. 251). Assim, cumpre a inclusão explícita da dimensão normativa no escopo dos estudos de causas, efeitos e desdobramentos da responsividade democrática.

O arbítrio de minorias, isto é, a representação política pautada por agendas que não são consenso entre todas as pessoas alcançadas pelas escolhas públicas nem sequer entre os respectivos públicos majoritários, sinaliza um descumprimento do compromisso democrático dos sistemas políticos (O'DWYER, 2005; SHAPIRO, 2006).

Após a apresentação do contexto teórico das instituições democráticas relevantes, são discutidos o modelo analítico observado, o tratamento qualitativo e quantitativo dos dados e os resultados obtidos. A conclusão é de que a exclusão e o descompasso do controle social, por falta de visibilidade dos temas ou captura das agendas por minorias, sugerem menor qualidade da representação exercida em sistemas políticos nominalmente democráticos e apontam para áreas ou temas de maior fragilidade regulatória. Nos apêndices, constam tabelas com os dados dos gastos públicos, dos registros de Plenário do Senado Federal e dos principais problemas nacionais brasileiros, além de detalhamentos metodológicos.

\section{Contexto teórico: instituições democráticas e escolhas públicas}

Os sistemas políticos respondem pelas escolhas públicas nacionais dotadas de coercitividade - authoritative public decisions (ALMOND et al., 2010). As assimetrias sistemáticas de informações atribuíveis aos sistemas políticos refletem e aprofundam as clivagens sociais entre as diversas categorias de públicos. Tal situação evidencia descumprimento continuado dos ideais normativos de redução das desigualdades categóricas e indica arquiteturas institucionais incompatíveis ou desalinhadas com as expectativas democráticas (TILly, 2007; DALTON, 2008).

Segundo Richard Posner (2003), a superação das críticas aos sistemas democráticos oriundas dos modelos deliberativos e elitistas (minimalistas) de democracia exige que a modelagem dos comportamentos e dos respectivos incentivos ocorra em bases positivas, mais do que normativas.

A democracia deliberativa enfatiza os pressupostos de ideias e habilidades cognitivas autônomas, para a manutenção e a ampliação de espaços públicos que lidem com agendas de opiniões públicas alternativas às dos agentes governamentais. O modelo elitista, por sua vez, destaca os sentimentos e desejos individuais, inclusive dos iletrados, nas escolhas dos representantes mediante eleições. 0 modelo deliberativo exige competências políticas que extrapolariam o tipo ideal do 
cidadão mediano, enquanto o modelo elitista ou minimalista afasta os cidadãos das escolhas públicas efetuadas pelos respectivos representantes. No primeiro caso, as alternativas de agendas não seriam competitivas, verdadeiramente, enquanto no segundo caso, a soberania popular terminaria no momento da posse dos representantes eleitos (POSNER, 2003).

A superação das críticas formuladas a esses modelos típicos da representação política democrática passa pelas questões informacionais, especialmente a redução das assimetrias entre agente e principal com mais controle social (SUNSTEIN, 2001; PEDERIVA; RenNó, 2015; O’DWYER, 2005).

Desse modo, a divulgação de informações pertinentes diminui tais assimetrias, aumenta a legitimidade da seleção dos agentes e a definição do grau adequado de delegação dos cidadãos aos agentes públicos, além de fortalecer o controle social e a qualidade da representação democrática. "Still, citizen-elite agreement is a basic standard for judging the representativeness of a democratic system. Agreement is a meaningful test because it [...] is a critical goal of representative democracy" (DALTON, 2008, p. 223).

Sunstein (2001) lembra que as deficiências informacionais induzem níveis inadequados de demandas regulatórias. Tais inadequações surgem como carências ou excessos de regulação. "When interest groups exploit cognitive mechanisms to create unwarranted fear or diminish concern with serious problems, it is desirable to have institutional safeguards" (SUNSTEIN, 2001, p. 236).

Assim, o risco regulatório ora versado remete à qualidade das instituições que regulam a prestação governamental de utilidades públicas submetidas à deliberação popular. A menor visibilidade dos critérios utilizados para essa prestação e a redução do controle social das agendas dos agentes públicos aumentam as chances de desvios e vieses regulatórios não democráticos e comportamentos inapropriados, eventualmente facultados ou até mesmo indevidamente legitimados pela regulação deficiente.

As duas primeiras condições informacionais e institucionais requeridas por North (1990) para um mercado político assemelhado ao modelo de custo transacional zero das trocas econômicas eficientes são que as partes afetadas saibam como as mudanças legislativas as afetarão e que isso seja comunicado aos agentes legisladores, os quais deveriam atuar fielmente de acordo com esse comunicado.

Assim, informações relevantes nas prestações de contas contribuem para a garantia institucional de níveis regulatórios adequados. Uma dessas informações consiste na identificação dos temas com riscos mais elevados de exploração indevida dos mecanismos cognitivos, que demandam mais regulação do que aqueles em que o controle social é mais evidente, conforme a correspondência das agendas. 
Para Krehbiel (1996), as teorias informacionais enfatizam o modo com que as instituições legislativas incentivam a especialização individual e o compartilhamento de conhecimentos políticos relevantes entre eventuais competidores por políticas distributivas. Numa organização legislativa informacional eficiente, as maiorias legislativas colhem frutos coletivos da especialização individual e controlam os benefícios distributivos, em lugar de conceder tais benefícios desproporcionalmente.

O controle da pauta legislativa faz com que o potencial efeito negativo de conflitos decorrentes da discussão de temas polêmicos ou controversos seja prevenido pela não colocação de tais temas em pauta (Cox; MCCUBBINS, 2005). Desse modo, o consenso majoritário prévio dos representantes marca os temas legislativos pautados nos plenários, instâncias deliberativas máximas e mais representativas do Poder Legislativo. Assim, a ausência de um tema em plenário evidencia o consenso pela sua não problematização, discussão e eventual alteração, o que também significa a opção pela manutenção dos incentivos institucionais e quadro de relações sociais vigentes.

A opinião parlamentar mediana transparece na seleção da pauta dos temas apresentados, deliberados ou decididos, mais do que as posições pontualmente favoráveis ou desfavoráveis (Cox; McCuBbins, 2005). Ademais, na democracia representativa brasileira, os parlamentares dispõem, formalmente, sobre todas as matérias de competência da respectiva esfera federada, mesmo sem anuência do Chefe do Executivo (BRASIL, 1988).

Assim, em um sistema político representativo democrático, as agendas de gastos públicos seriam congruentes com as agendas da população e dos seus representantes legislativos (Pederiva; RenNó, 2015; SorokA; WLEZIEN, 2010). Por conseguinte, os parâmetros obtidos da aferição da responsividade das agendas de gastos seriam relevantes do ponto de vista estatístico, com sinal positivo e similares para as agendas parlamentares - isto é, uma minoria detentora de recursos políticos - e da população representada.

Outras possibilidades de resultados seriam a responsividade não democrática, indicando comportamentos sistematicamente dissonantes das agendas de gastos em relação às agendas da população, ainda que coerentes com as agendas das minorias, ou a ausência de relações estatisticamente significativas. Essas duas últimas situações não se coadunam com o alegado compromisso democrático de representação.

As três possibilidades foram examinadas, de 2003 a 2009, com dados dos gastos federais brasileiros (CÂMARA DOS DEPUTADOS, 2010), dos registros de atividades no Plenário do Senado Federal (SEnAdo FederAL, 2010, 2011) e das pesquisas de opinião pública efetuadas pelo Latinobarômetro (2010) acerca do principal 
problema nacional. Tais dados estão disponíveis em páginas da internet e, com exceção dos dados de Plenário do Senado, processados pelos autores do presente trabalho, têm reconhecimento nacional e internacional em pesquisas acadêmicas afins de outros autores (PEDERIVA; RENNó, 2015).

\section{Modelo analítico}

Uma representação democrática substantiva pressupõe reduzidos níveis de assimetria informacional (PITKIN, 1967; SOROKA; WLEZIEN, 2010). O controle eficiente, eficaz e efetivo dos benefícios distributivos torna as agendas de políticas públicas de gastos governamentais congruentes com as agendas legislativas e da população. As diferenciações entre essas agendas podem ser atribuídas a atritos cognitivos e assimetrias informacionais, entendidos como desconhecimento das consequências das respectivas alternativas de escolhas ou apreciações morais ou ideológicas divergentes acerca dessas consequências. O ponto essencial é que, quanto mais discrepantes as agendas, maiores os empecilhos apresentados para o controle social democrático substantivo.

A diferenciação sistemática entre agendas pode decorrer de falhas estruturais nos processos de divulgação das informações relevantes, oriundas dos públicos e entre e para eles, ou de divergências contínuas no enquadramento ideológico das apreciações ou dos juízos efetuados acerca dos eventos. A primeira situação revela uma regulação informacional deficiente ou enviesada, enquanto as apreciações ou os juízos rotineiramente divergentes sugerem a falta de congruência ideológica entre representantes e representados. Ambas as situações sugerem falhas de representação política democrática e reduzem a qualidade das democracias (SOROKA; WLEZIEN, 2010).

Eventuais deficiências informacionais podem ser localizadas e corrigidas, pela adequada regulação das prestações de informações, inclusive nas contas anuais de governo. Nesse particular, a identificação das correspondências, entre as agendas das políticas governamentais, da população e dos agentes públicos, permite identificar os temas menos submetidos ao controle social e, potencialmente, mais carentes de regulação (O'DWYER, 2005; SUNSTEIN, 2001). Tal regulação visa diminuir os custos transacionais da representação política, aumentar os incentivos para que os diversos públicos deliberem de modo bem informado e estimular escolhas governamentais e políticas públicas mais aderentes aos atributos de representação política democrática substantiva.

Os juízos rotineiramente divergentes indicam diferenças ideológicas persistentes e altos riscos de potenciais conflitos de representatividade, ora traduzidos na ausência de responsividade democrática (PEDERIVA; RenNó, 2015). Tais conflitos 
fragilizam também a legitimidade das escolhas coletivas, a credibilidade das políticas públicas adotadas e a confiança na capacidade governativa de os agentes políticos conduzirem as expectativas nacionais de forma sustentável. Essa crise de confiança aumenta os custos transacionais para os agentes sociais - com reflexos, por exemplo, em taxas de juros e câmbio, no plano econômico - e sinaliza para mais chances futuras de índices piores de emprego, renda e satisfação com o desempenho da economia e do sistema político em geral.

Para os fins do presente trabalho, os índices não democráticos refletem o distanciamento sistemático entre as expectativas reveladas pelas agendas de gastos, pelos registros das atividades de plenário e pelas pesquisas de opinião pública sobre o principal problema nacional. A eventual indeterminação dos resultados aparece na forma da irrelevância estatística dos parâmetros obtidos, em decorrência da falta de informação suficiente para discriminar vínculos relevantes entre as variáveis observadas.

A comparação de três diferentes conjuntos de dados exige a elaboração de um índice analítico único, que permita a comparação das preferências alocativas, reveladas pelos gastos federais, pelas elites legislativas, mediante atividades de Plenário do Senado Federal, e pela população, por intermédio das pesquisas de opinião pública.

A unidade analítica macrotema viabiliza a comparação dos dados de gastos públicos federais, registros das atividades do Plenário do Senado e indicações do principal problema nacional. A formalização dessa ou outra categoria similar de macrotemas, capaz de incluir também outras formas de escolhas públicas e atividades de representação política, no ordenamento jurídico nacional, permitirá visão ainda mais ampla da diversidade democrática existente nos subsistemas políticos e dos pontos de maior ou menor fricção cognitiva e valorativa, isto é, dos graus de risco regulatório (PEDERIVA; RENNó, 2015).

Os gastos públicos observam a classificação funcional ou por finalidade, que expressa as grandes áreas temáticas dos gastos. Os registros das atividades de Plenário do Senado Federal constam das atas publicadas na internet. Tais registros podem ser categorizados conforme a classificação funcional. Essa classificação funcional, compactada em sete macrotemas, permite a comparação das preferências de gastos federais, em sua maioria, a cargo do Poder Executivo, com as preferências das elites legislativas, representadas nas atividades desse Plenário, e as indicações do principal problema nacional pela população (PEDERIVA; RENNó, 2015).

As áreas temáticas ora empregadas harmonizam-se, na medida do possível, com a Classificação das Funções do Governo (Cofog), patrocinada pela Organização das Nações Unidas e pelo Fundo Monetário Internacional. Essa classificação contém 
macrofunções e é internacionalmente indicada para os orçamentos públicos. Entretanto, o Brasil optou por criar uma categoria própria de funções, sem macrotemas ou macrofunções (MINISTÉRIO do PLANEJAMENTO, ORÇAMENTO E GESTÃo, 1999).

O Quadro 1 explicita os relacionamentos qualitativos entre as três classificações, com destaque para os sete macrotemas ora empregados - sem correspondência, trabalho, segurança, saúde, educação, direitos e administração.

\section{Quadro 1 - Problemas nacionais, macrotemas e funções orçamentárias}

\begin{tabular}{|c|c|c|}
\hline $\begin{array}{l}\text { Principal problema nacional } \\
\text { (Latinobarômetro) }\end{array}$ & Macrotema & $\begin{array}{c}\text { Função orçamentária } \\
\text { (Brasil) }\end{array}$ \\
\hline $\begin{array}{l}\text { Não respondeu } \\
\text { Não soube } \\
\text { Nenhum } \\
\text { Outros }\end{array}$ & 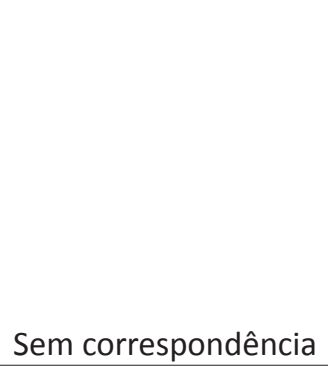 & $\begin{array}{l}\text { Encargos especiais } \\
\text { previdência social } \\
\text { Refinanciamento } \\
\text { Reserva de contingência }\end{array}$ \\
\hline $\begin{array}{c}\text { Baixo salário } \\
\text { Instabilidade laboral } \\
\text { Falta de trabalho }\end{array}$ & Trabalho & $\begin{array}{l}\text { Agricultura } \\
\text { Trabalho }\end{array}$ \\
\hline $\begin{array}{l}\text { Corrupção } \\
\text { Narcotráfico } \\
\text { Segurança pública } \\
\text { Terrorismo } \\
\text { Violencia }\end{array}$ & Segurança & $\begin{array}{l}\text { Essencial à justiça } \\
\text { judiciária }\end{array}$ \\
\hline $\begin{array}{c}\text { Consumo de droga } \\
\text { Saúde }\end{array}$ & Saúde & $\begin{array}{c}\text { Saneamento } \\
\text { Saúde }\end{array}$ \\
\hline Educação & Educação & $\begin{array}{c}\text { Ciência e tecnologia } \\
\text { Cultura } \\
\text { Educação } \\
\text { Desporto e lazer } \\
\end{array}$ \\
\hline $\begin{array}{c}\text { Pobreza } \\
\text { Distribuição de renda } \\
\text { Discriminação racial } \\
\text { Habitação }\end{array}$ & & $\begin{array}{c}\text { Assistência social } \\
\text { Organização agrária } \\
\text { Habitação } \\
\text { Urbanismo }\end{array}$ \\
\hline
\end{tabular}




\begin{tabular}{|c|c|c|}
\hline $\begin{array}{l}\text { Principal problema nacional } \\
\text { (Latinobarômetro) }\end{array}$ & Macrotema & $\begin{array}{c}\text { Função orçamentária } \\
\text { (Brasil) }\end{array}$ \\
\hline \multicolumn{3}{|l|}{ Inserção de jovens } \\
\hline Meio ambiente & & Gestão ambiental \\
\hline Violação de direitos & Direitos & Direitos da cidadania \\
\hline \multirow[t]{2}{*}{ Crise política } & & Administração \\
\hline & & Legislativa \\
\hline \multirow[t]{2}{*}{ Economía } & & Comércio e serviços \\
\hline & & Indústria \\
\hline Transporte & & Transporte \\
\hline Fronteiras & & Defesa \\
\hline \multicolumn{3}{|l|}{ Inflação } \\
\hline País vizinho & & Relações exteriores \\
\hline Aquecimento global & & Energia \\
\hline Serviço básico & Administração & Comunicações \\
\hline
\end{tabular}

Fonte: Pederiva e Rennó (2015).

O macrotema sem correspondência identifica a falta de correspondência entre as funções orçamentárias e os problemas apontados pela população nas pesquisas do Latinobarômetro. Segundo o Quadro 1, estão nesse grupo assuntos recorrentes para aqueles que lidam diuturnamente com finanças públicas: previdência social, encargos especiais, refinanciamento (da dívida pública) e reserva de contingência.

As funções orçamentárias incluídas no macrotema sem correspondência não têm visibilidade perante a opinião pública, embora representem parcela significativa e relevante das escolhas públicas, vinculadas diretamente a escolhas intertemporais. Assim, previdência social e dívida pública (encargos especiais e refinanciamento) são desconsideradas pela população como problemas nacionais, embora alberguem cerca de $85 \%$ dos gastos públicos federais (Apêndice A). Isso indica que esses temas estão sendo satisfatoriamente atendidos, simplesmente esquecidos ou percebidos como inalcançáveis ou fora do escopo deliberativo dos indivíduos pesquisados (PEDERIVA; RenNó, 2015).

No âmbito quantitativo, cada um dos sete macrotemas aparece como uma proporção dos respectivos totais anuais de gastos, registros ou indicações. A relevância dessas funções vinculadas diretamente a escolhas intertemporais para as finanças públicas decorre da sua materialidade. Desse modo, a população delibera sobre temas que abrangem apenas cerca de $15 \%$ dos gastos federais. Tal descompasso justifica a preocupação com riscos regulatórios mais elevados nessas temáticas.

Tal situação persiste ao longo das três agendas de gastos, que seguem as etapas do processamento da despesa pública: 1) lei orçamentária anual (lei), com promessas 
de solução futura de conflitos distributivos presentes na forma de autorizações para gastos especificados no ano seguinte; 2) execução das autorizações orçamentárias (executado), na forma do comprometimento dessas autorizações para a solução diferida dos conflitos distributivos encaminhados no passado; 3) desembolsos efetuados, pelo Tesouro Nacional (pago), com base nas autorizações orçamentárias, ou seja, a solução presente de conflitos distributivos encaminhados no mesmo ciclo orçamentário.

A reserva de contingência consiste numa categoria de recursos previstos nas leis orçamentárias, apropriáveis ao longo da execução do orçamento, e não tem relevância para este exame, assim como os demais integrantes do macrotema sem correspondência (Apêndices B e C).

A verificação da correspondência de agendas da população e do Senado Federal com os gastos federais recomenda ainda a introdução de uma variável que sinaliza os anos maiores do que 2005. Houve mudança de padrão, durante o período examinado, na tramitação da lei orçamentária federal até sua vigência. Após o atraso de mais de 200 dias, em 2000, houve um período de relativa estabilidade, até 2005 , em que a maior defasagem foi de aproximadamente 25 dias. Contudo, em 2006, houve novo atraso, de quase 150 dias, e um comportamento de altos e baixos aderente aos ciclos eleitorais brasileiros. Desse modo, a introdução dessa variável distingue dois padrões diferentes no relacionamento entre os Poderes Executivo e Legislativo federais (PEDERIVA; RenNó, 2015).

O modelo detalhado da regressão consta do Apêndice D.

\section{Resultados obtidos e análise}

A Tabela 1 apresenta os resultados das nove regressões. Verifica-se, em cada agenda de gasto - lei, executado ou pago -, a possibilidade de correspondências com até dois anos de diferença em relação às agendas de Senado e população.

Tabela 1 - Graus de responsividade

\begin{tabular}{cccc}
\hline & \multicolumn{3}{c}{ Brasil } \\
\hline públicos & Lei & Executado & Pago \\
\hline $\mathrm{t}$ & & & $0,54^{* * *}$ \\
senado & $0,77^{* * * *}$ & $0,59^{* * *}$ & 0,01 \\
$\mathrm{p}$ & 0 & 0,01 & $-0,46^{* *}$ \\
população & $-0,25$ & $-0,56^{* * * *}$ & 0,04 \\
$\mathrm{p}$ & 0,4 & 0 &
\end{tabular}




\begin{tabular}{|c|c|c|c|}
\hline & \multicolumn{3}{|c|}{ Brasil } \\
\hline públicos & Lei & Executado & Pago \\
\hline ano $>2005$ & $0,11 * * * *$ & $0,15 * * * *$ & $0,14 * * * *$ \\
\hline$p$ & 0 & 0 & 0 \\
\hline constante & $-3,82 * * * *$ & $-3,62 * * * *$ & $-3,73 * * * *$ \\
\hline$p$ & 0 & 0 & 0 \\
\hline observações & 42 & 42 & 42 \\
\hline chi2 & 33,45 & 34,12 & 21,43 \\
\hline \multicolumn{4}{|l|}{$t+1$} \\
\hline senado & $0,90 * * * *$ & $0,67 * * *$ & $0,59 * *$ \\
\hline$p$ & 0 & 0 & 0,02 \\
\hline população & 0 & 0,22 & 0,26 \\
\hline$p$ & 0,99 & 0,48 & 0,44 \\
\hline ano $>2005$ & $0,29 * * * *$ & $0,17 * * * *$ & $0,12 * * * *$ \\
\hline$p$ & 0 & 0 & 0 \\
\hline constante & $-4,00 * * * *$ & $-3,70 * * * *$ & $-3,78 * * * *$ \\
\hline$p$ & 0 & 0 & 0 \\
\hline observações & 42 & 36 & 36 \\
\hline chi2 & 417 & 47,85 & 41,72 \\
\hline \multicolumn{4}{|l|}{$t+2$} \\
\hline senado & $0,85 * * * *$ & $0,63 * * *$ & $0,50 * *$ \\
\hline$p$ & 0 & 0,01 & 0,03 \\
\hline população & $-0,19$ & $-0,54$ & $-0,4$ \\
\hline$p$ & 0,63 & 0,09 & 0,2 \\
\hline ano $>2005$ & $0,33 * * * *$ & $0,12 * * * *$ & $0,12 * * * *$ \\
\hline$p$ & 0 & 0 & 0 \\
\hline constante & $-3,93 * * * *$ & $-3,56 * * * *$ & $-3,68 * * * *$ \\
\hline$p$ & 0 & 0 & 0 \\
\hline observações & 36 & 30 & 30 \\
\hline chi2 & 151,29 & 71,08 & 27,86 \\
\hline
\end{tabular}

As três agendas de gastos apresentam correspondências significativas, a 5\%, e positivas com as agendas do Plenário do Senado Federal em todas as defasagens temporais. A relação mais intensa ocorre com um ano de defasagem, ou seja, a mudança de agenda legislativa em um ano tem a maior correspondência no gasto do ano seguinte.

Outra observação relevante é que os parâmetros de Senado diminuem, da esquerda para a direita, ou seja, de uma etapa da despesa pública para a seguinte, observando a crescente participação do Poder Executivo. Tal resultado comprova a estabilização cada vez maior das expectativas quanto à solução distributiva dos acordos pactuados ao longo do processamento dos gastos públicos. 
A população, diferentemente de senado, não obtém responsividade democrática dos gastos públicos. Além da falta de correspondência significativa entre indicações da população e gastos do mesmo ano, a 5\%, destaca-se a responsividade não democrática dos gastos executado e pago do mesmo ano em relação à população. Esse resultado evidencia antagonismo sistemático, na esfera do Poder Executivo, entre gastos e preferências populares.

Dessa maneira, comprovado está o desalinhamento entre as respectivas agendas de agentes públicos federais - eleitos ou não, nos Poderes Executivo e Legislativo - em relação aos seus representados políticos. Isso significa que, em lugar de caixa de ressonância da vontade popular, o Plenário do Senado atua com agendas próprias, em combinação com o Poder Executivo, principal responsável pela execução orçamentária e financeira.

O risco regulatório associado às assimetrias informacionais e de expectativas correspondentes aparece na falta de correspondência relevante entre gastos e agendas populares e no antagonismo sistemático entre esses gastos e a indicações da população.

A mudança no padrão dos gastos, depois de 2005, por conta das mudanças, nas relações entre os Poderes Legislativo e Executivo, é significativa, a 1\%, em todas as agendas de gastos e intervalos temporais. $O$ resultado aponta para a necessidade de maior controle social do risco regulatório, especialmente no tocante à dívida pública e à previdência social, dado que ambos os Poderes são agentes da população.

O intercepto negativo, também relevante, recomenda o aperfeiçoamento do modelo de responsividade democrática empregado, por mudanças de critérios e incorporação de outros dados.

Os avanços desse modelo analítico incluem a regulamentação do seu uso nas análises de prestações de contas, inclusive com o detalhamento dos fluxos informacionais por temática de política pública no País. Diferentes temas contam com históricos distintos de mobilização, além de públicos dotados de diferentes recursos de poder que influenciam e são influenciados de maneira diversa pelas ações governamentais.

Por exemplo, Pederiva e Rennó (2015) identificaram a ausência de responsividade democrática das agendas de gastos em relação às agendas dos públicos específicos que aprovaram o governo, estavam em melhor situação econômica, apresentaram escolaridade mais elevada ou eram do gênero masculino.

Todavia, quando observada a responsividade da população e desses públicos específicos aos gastos governamentais, as agendas de gastos precederam em até dois anos as agendas populares, com particular destaque para o público com escolaridade mais elevada (PEDERIVA; RENNó, 2015). Como tais resultados foram obtidos de forma 
agregada, outro desdobramento recomendável das pesquisas sobre responsividade democrática consiste em detalhar cada uma dessas relações, conforme a temática e o público, para aferição da efetividade da autonomia da participação popular, assim como dos incentivos institucionais operados nessa direção.

Ademais, existe a possibilidade de os resultados ora apresentados mudarem, por conta de questões metodológicas, como as fontes dos dados, os critérios de agregação e os modos de ligação entre as variáveis. Essa última restrição aumenta o mérito da estabilização e da uniformização normativas da coleta e do tratamento de dados para a apuração dos indicadores de responsividade democrática. Tal normatização inclui a mobilização de outros recursos públicos e outras formas de atividades de representação e escolhas públicas, além da especialização de temas e públicos, como já mencionado.

\section{Conclusão}

As narrativas em torno da conexão orçamentária e da responsividade democrática desvelam, entre outras coisas, os graus de correspondência entre as preferências reveladas pelas agendas de diferentes públicos. Os indicadores de responsividade democrática sintetizam a qualidade democrática dos elos entre governantes e governados, por exemplo, no domínio da qualidade dos gastos públicos. Ao mesmo tempo, eles identificam situações em que há risco regulatório mais elevado, associado à responsividade não democrática, isto é, quando a mobilização de agendas prestigia públicos aparentemente minoritários, ou à falta de correspondência significativa entre as diversas agendas.

O confronto dessas agendas identifica temas com maior risco regulatório, como dívida pública e previdência social. A aparente invisibilidade desses temas para a população, ainda que representem $85 \%$ dos gastos federais, sugere que os critérios de mobilização desses recursos são formados sem o crivo deliberativo dos públicos supostamente representados. A falta de percepção da população quanto à qualidade das escolhas coletivas efetuadas nesses temas sugere menor controle social e aponta para a necessidade de maiores garantias institucionais formais específicas de aderência dos agentes públicos aos preceitos de representação democrática substantiva.

Embora esses temas continuem sem visibilidade junto à opinião pública latinoamericana pesquisada pelo Latinobarômetro (2015), incluindo o Brasil, a dívida pública e a previdência social foram temas nacionais que apareceram, a partir de 2012, nas pesquisas de opinião pública da Comunidade Europeia, realizadas pelo Eurobarômetro (COMISSÃo EUROPEIA, 2012). Essa inclusão demonstra melhoria democrática da qualidade do gerenciamento do risco regulatório e do controle 
social exercidos no âmbito daqueles sistemas políticos, que, infelizmente, ainda não alcançou as sociedades latino-americanas.

Outro fator de risco regulatório para a democracia brasileira consiste na carência de instrumentos institucionalizados que explicitem a eventual captura das agendas distributivas por públicos minoritários dotados de mais recursos de poder político. Nesse sentido, a responsividade democrática das diversas agendas de gastos às agendas das elites legislativas que controlam o Plenário do Senado Federal contrasta com a indiferença ou até o antagonismo estabelecido entre pautas de gastos e pautas populares, especialmente no âmbito do Poder Executivo.

Ambas as situações - exclusão ou enfraquecimento do controle social, por falta de visibilidade do tema perante a opinião pública, e captura de agendas de políticas públicas por minorias - sugerem fragilidades regulatórias nos sistemas democráticos de representação política. Tais fragilidades indicam áreas temáticas demandantes de maior consideração ética e normativa, de modo que os espaços deliberativos incluam números crescentes de pessoas alcançadas pelos efeitos das escolhas governamentais. A autonomia e a efetividade dos mecanismos institucionais voltados para o incremento da participação popular também podem ser aferidas pelos indicadores de responsividade democrática.

Os custos transacionais para estabelecer e manter, individualmente, instituições analíticas capazes de compactar os dados e obter as informações relevantes sobre o sistema político, em uma visão sinóptica, são proibitivos. Desse modo, o modelo analítico ora empregado aponta para um projeto de pesquisa ambicioso, que visa ao aperfeiçoamento regulatório da accountability governamental e do controle social democráticos, com vistas ao aperfeiçoamento da gestão da coisa pública brasileira e da representação exercida no bojo desse sistema político.

Considerando a possibilidade de que cada subsistema do sistema político adote um índice temático harmonizado com os demais subsistemas, cabe sugerir a adoção compulsória, em norma geral ou nos respectivos ordenamentos jurídicos, do modelo analítico ora apresentado, especialmente nas prestações de contas submetidas ao julgamento parlamentar e ao controle social, além da disseminação dos dados analíticos e dos indicadores de responsividade democrática na forma de dados abertos governamentais (PEDERIVA; RENNó, 2015).

A adoção de indicadores contábeis harmonizados de responsividade democrática, em todas as esferas e domínios das administrações públicas, inclusive internacionais, ampliaria ainda mais as possibilidades do exame comparado da qualidade democrática dos sistemas políticos e dos temas mais expostos a riscos regulatórios, com inequívocos benefícios para a qualidade da representação política e da gestão democrática da coisa pública. 


\section{Referências bibliográficas}

Almond, G. A.; Powell JR., G. B. J.; Dalton, R. J.; StrøM K. Comparative politics today: a world view. 9th ed. New York: Longman, 2010.

BRASIL. Constituição da República Federativa do Brasil, de 5 de outubro de 1988. Disponível em: < http://www.planalto.gov.br/ccivil_03/Constituicao/Constituicao. htm>. Acesso em: 30 mai. 2013.

CÂMARA dos DeputAdos (CD). Execução orçamentária. 2010. Disponível em: <http:// www2.camara.gov.br/atividade-legislativa/orcamentobrasil/orcamentouniao/loa/ execucao.html>. Acesso em: 5 jun. 2010.

Cameron, A. C.; TrivedI, P. K. Microeconometrics using STATA. Revised Edition. College Station: Stata Press, 2010.

COMISSÃo EUROPEIA (CE). Eurobarometer surveys. 2015. Disponível em: <http:// ec.europa.eu/public_opinion/index_en.htm>. Acesso em: 10.3.2015.

Cox, G. W.; MccubBins, M. D. Setting the agenda: responsible party government in the U.S. House of Representatives. Cambridge: Cambridge University Press, 2005.

DALTON, R. J. Citizen politics: public opinion and political parties in advanced industrial democracies. 5th. ed. Washington: CQ Press, 2008.

Downs, A. An economic theory of democracy. Boston: Addison-Wesley, 1957.

Governmental Accounting StAndards BoARd (GASB). Governmental Accounting Research System (GARS). Atualizado até 31 dez. 2001. 2002. CD-ROM.

GonzÁlez, Suzana Magdalena Patiño. La responsividad ética. Madrid, México: Plaza y Valdés, 2010.

INSTITUTO DE Pesquisa EConômica Aplicada (IPEA). IpeaData. 2010. Disponível em: <http://www.ipeadata.gov.br/ipeaweb.dll/ipeadata?65370046>. Acesso em: 5 jun. 2010.

KREHBIEL, Keith. Information and legislative organization. Ann Arbor: The University of Michigan Press, 1996.

LATINOBARÔMETRO. Latinobarómetro: opinión pública latinoamericana. 2010. Disponível em: <http://www.latinobarometro.org/latino/latinobarometro.jsp>. Acesso em: 26 dez. 2010.

Análisis online. 2015. Disponível em: <http://www.latinobarometro. org/latOnline.jsp>. Acesso em: 10.5.2015.

MATTESSICH, R. Critique of accounting: examination of the foundations and normative structure of an applied discipline. USA: Quorum Books, 1995.

Ministério do Planejamento, OrÇamento e Gestão (MPOG). Portaria $n$ o 42, de 14 de abril de 1999. Atualiza a discriminação da despesa por funções de que tratam o

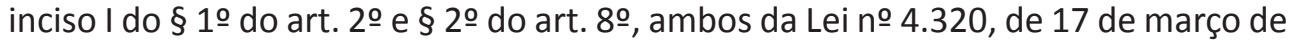
1964, estabelece os conceitos de função, subfunção, programa, projeto, atividade, operações especiais, e dá outras providências. 1999. Disponível em: <http://www. stn.fazenda.gov.br/legislacao/download/contabilidade/portaria42.pdf>. Acesso em: 5 jun. 2008. 
NORTH, Douglass C. Institutions, institutional change and economic performance. Cambridge: Cambridge University, 1990.

O'DWYER, B. Stakeholder democracy: challenges and contributions from social accounting. Business Ethics: A European Review, 14(1), p. 28-41, 2005.

Pederiva, João Henrique; Rennó, Lucio. Responsividade democrática no Brasil de Lula e na Argentina dos Kirchner. Jundiaí: Paco Editorial, 2015.

PITKIN, H. F. The concept of representation. Los Angeles: University of California Press, 1967.

Posner, R. A. Law, pragmatism, and democracy. Cambridge: Harvard University Press, 2003.

ShAPIRO, Ian. Os fundamentos morais da política. São Paulo: Martins Fontes, 2006. Senado Federal (SF). Diário do Senado Federal. 2010. Disponível em: <http:// www.senado.gov.br/publicacoes/diarios/asp/Diarios.asp?TIP_PAGINA=SENADO>. Acesso em: 5 jun. 2010.

Portal publicações: diários. 2011. Disponível em: < http://www6. senado.gov.br/diarios/Diario >. Acesso em: 30 mar. 2011.

SOROKA, S. N.; WLEZIEN, C. Degrees of democracy: politics, public opinion, and policy. Cambridge: Cambridge University Press, 2010.

SUNSTEIN, C. Cognition and cost-benefit analysis. In: Cost-benefit analysis: legal, economic, and philosophical perspectives. Chicago: The University of Chicago Press, 2001.

TILly, C. Democracy. Cambridge: Cambridge University Press, 2007.

\section{Apêndice A - Funções orçamentárias brasileiras}

A Tabela A.1 identifica as trinta funções empregadas para a determinação dos gastos orçamentários federais brasileiros autorizados no período de 2003 a 2010, em milhões de reais com poder aquisitivo de 2009. Desse total, $84 \%$ estiveram distribuídos pelo refinanciamento da dívida (45\%), pelos encargos especiais (24\%) e previdência social (14\%).

Tabela A.1 - Brasil: lei orçamentária (R\$ milhões de 2009) - agenda de gasto lei

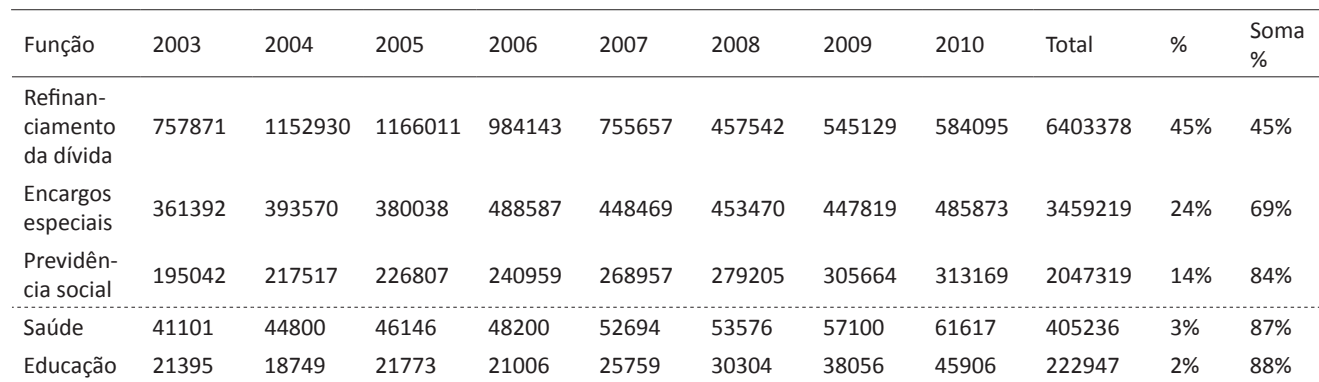




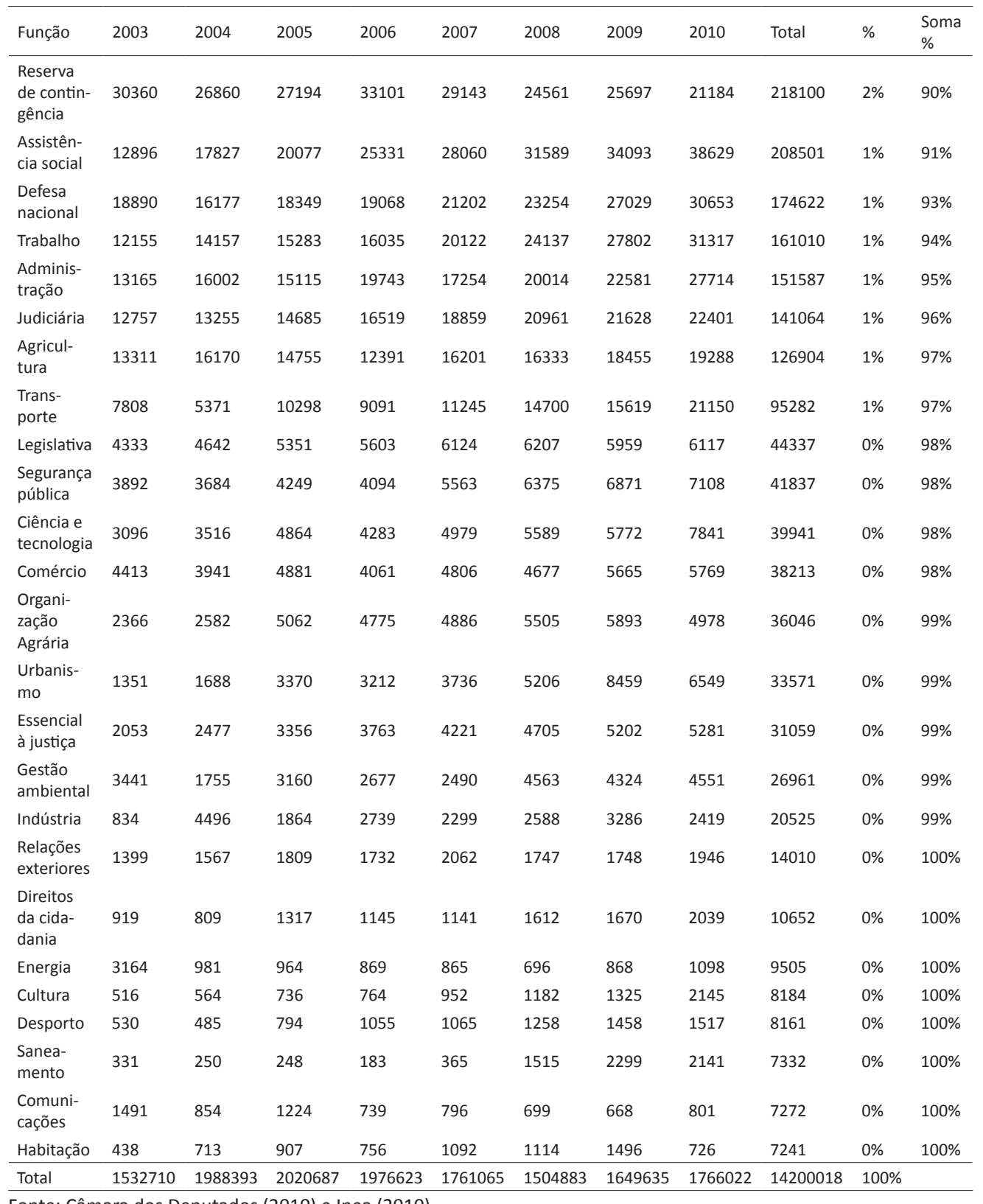

Fonte: Câmara dos Deputados (2010) e Ipea (2010).

No contexto do orçamento federal executado brasileiro, a Tabela A.2 indicou que as principais funções continuaram sendo encargos especiais (35\%), refinanciamento da dívida (29\%) e previdência social (19\%). Juntas, elas alcançaram $83 \%$ do total da execução orçamentária no período. 
Tabela A.2 - Brasil: executado (R\$̦ milhões de 2009) - agenda de gasto executado

\begin{tabular}{|c|c|c|c|c|c|c|c|c|c|c|}
\hline Função & 2003 & 2004 & 2005 & 2006 & 2007 & 2008 & 2009 & Total & $\%$ & $\begin{array}{l}\text { Soma } \\
\%\end{array}$ \\
\hline $\begin{array}{l}\text { Encargos espe- } \\
\text { ciais }\end{array}$ & 347556 & 318874 & 311755 & 524560 & 509560 & 580597 & 557476 & 3150377 & $35 \%$ & $35 \%$ \\
\hline $\begin{array}{l}\text { Refinanciamen- } \\
\text { to da dívida }\end{array}$ & 483611 & 439228 & 589830 & 373831 & 326493 & 193663 & 261610 & 2668266 & $29 \%$ & $64 \%$ \\
\hline $\begin{array}{l}\text { Previdência } \\
\text { social }\end{array}$ & 196903 & 208193 & 224357 & 245747 & 258910 & 269735 & 291079 & 1694924 & $19 \%$ & $83 \%$ \\
\hline Saúde & 36777 & 41477 & 43421 & 46823 & 50499 & 52300 & 58149 & 329446 & $4 \%$ & $86 \%$ \\
\hline Educação & 19252 & 18281 & 19267 & 22694 & 26896 & 29469 & 36680 & 172539 & $2 \%$ & $88 \%$ \\
\hline $\begin{array}{l}\text { Assistência } \\
\text { social }\end{array}$ & 11391 & 17438 & 18812 & 24873 & 27301 & 30089 & 33336 & 163240 & $2 \%$ & $90 \%$ \\
\hline Defesa nacional & 15660 & 17073 & 18355 & 19441 & 21613 & 23440 & 26147 & 141730 & $2 \%$ & $92 \%$ \\
\hline Trabalho & 12851 & 13468 & 15136 & 19102 & 21820 & 23674 & 29301 & 135352 & $1 \%$ & $93 \%$ \\
\hline Judiciária & 11315 & 13247 & 12705 & 16763 & 17740 & 19605 & 20464 & 111840 & $1 \%$ & $94 \%$ \\
\hline Administração & 9966 & 11242 & 10813 & 12781 & 15581 & 15410 & 17078 & 92870 & $1 \%$ & $95 \%$ \\
\hline Agricultura & 8806 & 9605 & 9912 & 11711 & 12532 & 10194 & 14723 & 77483 & $1 \%$ & $96 \%$ \\
\hline Transporte & 4125 & 4594 & 8002 & 8037 & 13514 & 13679 & 16505 & 68456 & $1 \%$ & $97 \%$ \\
\hline $\begin{array}{l}\text { Segurança } \\
\text { pública }\end{array}$ & 3255 & 3482 & 3592 & 4514 & 5847 & 6865 & 7991 & 35546 & $0 \%$ & $97 \%$ \\
\hline Legislativa & 4162 & 4448 & 4531 & 5493 & 5470 & 5536 & 5164 & 34804 & $0 \%$ & $98 \%$ \\
\hline $\begin{array}{l}\text { Ciência e tecno- } \\
\text { logia }\end{array}$ & 2698 & 3279 & 3897 & 4406 & 4781 & 5450 & 6190 & 30701 & $0 \%$ & $98 \%$ \\
\hline $\begin{array}{l}\text { Organização } \\
\text { agrária }\end{array}$ & 1935 & 3293 & 4264 & 4903 & 5361 & 4717 & 4845 & 29319 & $0 \%$ & $98 \%$ \\
\hline $\begin{array}{l}\text { Essencial à } \\
\text { justiça }\end{array}$ & 1835 & 2674 & 2774 & 3545 & 4125 & 4769 & 4995 & 24718 & $0 \%$ & $99 \%$ \\
\hline Comércio & 2798 & 2621 & 3385 & 3222 & 3177 & 3521 & 4036 & 22759 & $0 \%$ & $99 \%$ \\
\hline Urbanismo & 464 & 1501 & 2512 & 2482 & 4893 & 4528 & 4711 & 21091 & $0 \%$ & $99 \%$ \\
\hline $\begin{array}{l}\text { Gestão am- } \\
\text { biental }\end{array}$ & 1283 & 1501 & 2371 & 1857 & 3579 & 3916 & 3697 & 18203 & $0 \%$ & $99 \%$ \\
\hline Indústria & 594 & 1948 & 1779 & 2385 & 3115 & 2377 & 1602 & 13802 & $0 \%$ & $99 \%$ \\
\hline $\begin{array}{l}\text { Relações exte- } \\
\text { riores }\end{array}$ & 1575 & 1650 & 1820 & 1612 & 1634 & 2005 & 1549 & 11845 & $0 \%$ & $100 \%$ \\
\hline Energia & 5285 & 498 & 561 & 518 & 600 & 557 & 810 & 8829 & $0 \%$ & $100 \%$ \\
\hline $\begin{array}{l}\text { Direitos da } \\
\text { cidadania }\end{array}$ & 533 & 692 & 987 & 1134 & 1046 & 1575 & 1569 & 7536 & $0 \%$ & $100 \%$ \\
\hline Saneamento & 80 & 97 & 105 & 65 & 1718 & 1859 & 3019 & 6942 & $0 \%$ & $100 \%$ \\
\hline Habitação & 165 & 615 & 678 & 1347 & 663 & 1090 & 1011 & 5569 & $0 \%$ & $100 \%$ \\
\hline Desporto & 217 & 341 & 503 & 852 & 1563 & 1006 & 982 & 5463 & $0 \%$ & $100 \%$ \\
\hline Cultura & 313 & 408 & 588 & 670 & 836 & 937 & 1120 & 4872 & $0 \%$ & $100 \%$ \\
\hline Comunicações & 868 & 624 & 572 & 553 & 1001 & 554 & 534 & 4705 & $0 \%$ & $100 \%$ \\
\hline Total & 1186273 & 1142393 & 1317284 & 1365922 & 1351867 & 1313116 & 1416373 & 9093228 & $100 \%$ & \\
\hline
\end{tabular}

Fonte: Câmara dos Deputados (2010) e Ipea (2010).

A Tabela A.3, com os valores pagos no período, confirmou a consistência da preponderância dessas três funções também nesse âmbito. Dessa forma, encargos especiais (35\%), refinanciamento da dívida (31\%) e previdência social (19\%) absorveram $85 \%$ dos pagamentos autorizados orçamentariamente. 
Tabela A.3 - Brasil: pago (R\$ milhões de 2009) - agenda de gasto pago

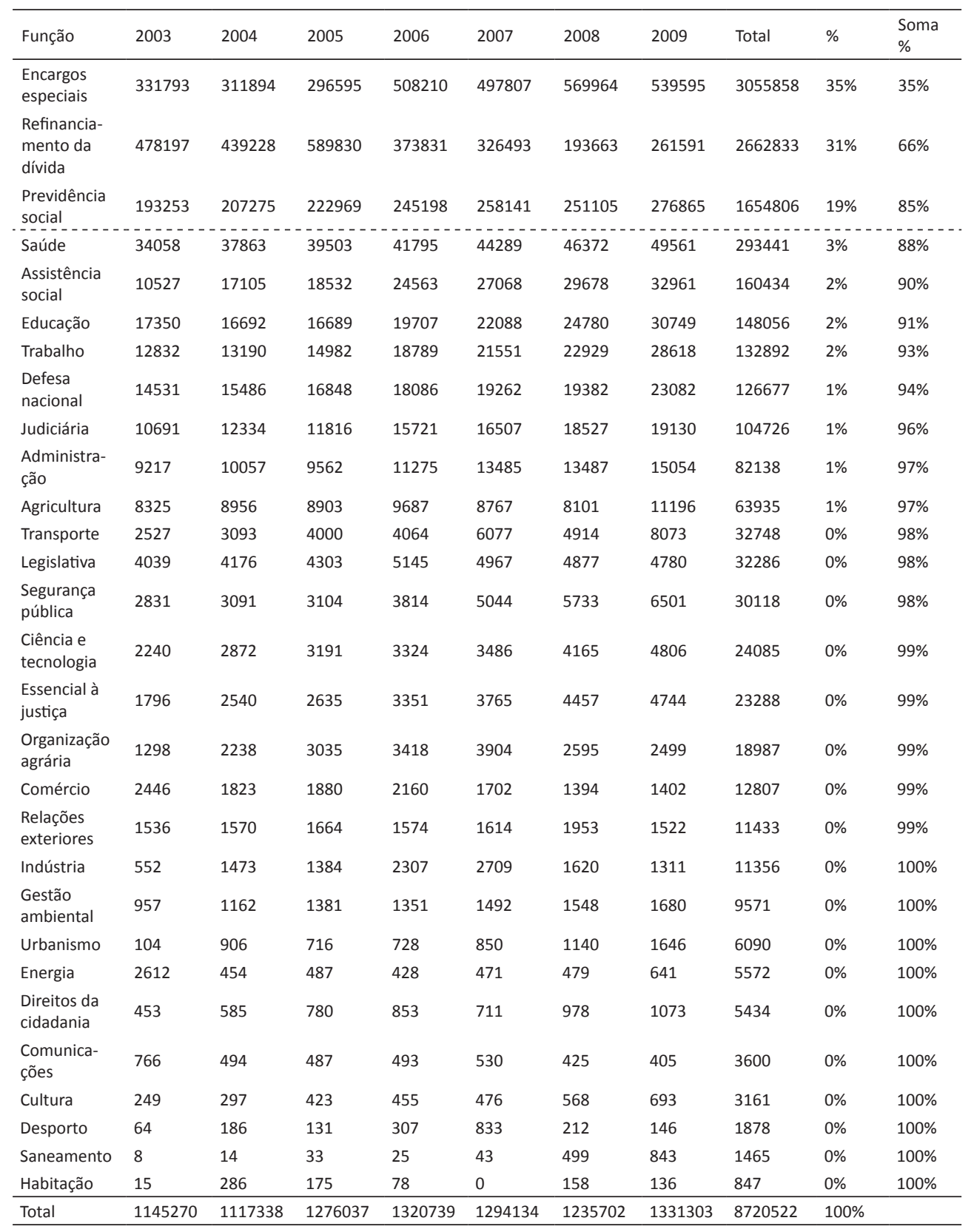

Fonte: Câmara dos Deputados (2010) e Ipea (2010).

Assim, as três tabelas acima evidenciaram que os maiores gastos orçamentários federais brasileiros foram com arbitramentos intertemporais. Os encargos especiais representaram a devolução ou o ressarcimento dos créditos que financiaram as ações adotadas no passado. Assim, eles expressaram as decisões de adimplemento 
das obrigações cujos benefícios já foram usufruídos. O refinanciamento da dívida remeteu às contrapartidas financeiras que foram diferidas para um futuro mais ou menos distante, mediante a contratação de novas obrigações para o adimplemento das anteriores.

\section{Apêndice B - Brasil: registros do Plenário do Senado}

Os órgãos legislativos encarregados dos registros e da operacionalização das pautas adotam classificações temáticas próprias, distintas das classificações orçamentárias. Nesse sentido, a categorização dos registros das atas das sessões legislativas, conforme a classificação funcional, não acrescentaria custos de processamento, mas exigiria um compromisso recíproco entre os órgãos e as entidades competentes para editar essas classificações.

A classificação constante da Tabela B é obra do autor do presente artigo. Além de termos-chave, a classificação verifica o contexto de todas as atividades registradas. Assim, as tomadas de posições, mediante discursos, proposições, deliberações e votações são equiparadas como formas equivalentes de representação política. Há inclusão na função legislativa das questões regimentais e de encaminhamento das matérias. Caso as informações de sumário não sejam suficientes para associar direta e imediatamente a outra função, o registro também é computado na função legislativa.

Tabela B - Brasil: registros de Plenário por função orçamentária (agenda de elite)

\begin{tabular}{|c|c|c|c|c|c|c|c|c|c|c|}
\hline $\begin{array}{l}\text { Funções } \\
\text { compactadas }\end{array}$ & 2003 & 2004 & 2005 & 2006 & 2007 & 2008 & 2009 & Total & $\%$ & Soma \% \\
\hline Legislativa & 3693 & 3186 & 4427 & 3546 & 4262 & 4961 & 4648 & 28723 & $28 \%$ & $28 \%$ \\
\hline Comunicações & 3074 & 3827 & 3589 & 2811 & 1873 & 1640 & 3041 & 19855 & $19 \%$ & $47 \%$ \\
\hline Administração & 1149 & 1144 & 1356 & 766 & 893 & 924 & 926 & 7158 & $7 \%$ & $54 \%$ \\
\hline Cultura & 652 & 514 & 860 & 677 & 774 & 484 & 1430 & 5391 & $5 \%$ & $59 \%$ \\
\hline $\begin{array}{l}\text { Relações } \\
\text { exteriores }\end{array}$ & 644 & 623 & 679 & 508 & 831 & 866 & 987 & 5138 & $5 \%$ & $64 \%$ \\
\hline Judiciária & 380 & 423 & 546 & 521 & 787 & 1398 & 702 & 4757 & $5 \%$ & $69 \%$ \\
\hline Educação & 272 & 346 & 475 & 416 & 740 & 654 & 397 & 3300 & $3 \%$ & $72 \%$ \\
\hline Transporte & 442 & 355 & 332 & 468 & 533 & 768 & 297 & 3195 & $3 \%$ & $75 \%$ \\
\hline Saúde & 327 & 283 & 340 & 429 & 368 & 548 & 261 & 2556 & $2 \%$ & $78 \%$ \\
\hline $\begin{array}{l}\text { Comércio e } \\
\text { serviços }\end{array}$ & 426 & 299 & 236 & 232 & 339 & 616 & 326 & 2474 & $2 \%$ & $80 \%$ \\
\hline $\begin{array}{l}\text { Gestão } \\
\text { ambiental }\end{array}$ & 243 & 184 & 384 & 190 & 312 & 633 & 230 & 2176 & $2 \%$ & $82 \%$ \\
\hline $\begin{array}{l}\text { Segurança } \\
\text { pública }\end{array}$ & 205 & 167 & 205 & 310 & 504 & 306 & 196 & 1893 & $2 \%$ & $84 \%$ \\
\hline Trabalho & 215 & 166 & 139 & 234 & 355 & 458 & 179 & 1746 & $2 \%$ & $86 \%$ \\
\hline $\begin{array}{l}\text { Direitos da } \\
\text { cidadania }\end{array}$ & 161 & 157 & 194 & 160 & 286 & 628 & 155 & 1741 & $2 \%$ & $87 \%$ \\
\hline Agricultura & 189 & 152 & 213 & 350 & 335 & 378 & 85 & 1702 & $2 \%$ & $89 \%$ \\
\hline
\end{tabular}




\begin{tabular}{|c|c|c|c|c|c|c|c|c|c|c|}
\hline $\begin{array}{l}\text { Funções } \\
\text { compactadas }\end{array}$ & 2003 & 2004 & 2005 & 2006 & 2007 & 2008 & 2009 & Total & $\%$ & Soma \% \\
\hline $\begin{array}{l}\text { Assistência } \\
\text { social }\end{array}$ & 228 & 301 & 321 & 174 & 181 & 195 & 236 & 1636 & $2 \%$ & $91 \%$ \\
\hline $\begin{array}{l}\text { Encargos } \\
\text { especiais }\end{array}$ & 268 & 210 & 137 & 218 & 236 & 182 & 385 & 1636 & $2 \%$ & $92 \%$ \\
\hline Energia & 232 & 189 & 208 & 250 & 248 & 274 & 182 & 1583 & $2 \%$ & $94 \%$ \\
\hline $\begin{array}{l}\text { Essencial à } \\
\text { justiça }\end{array}$ & 86 & 67 & 146 & 176 & 345 & 303 & 148 & 1271 & $1 \%$ & $95 \%$ \\
\hline $\begin{array}{l}\text { Previdência } \\
\text { social }\end{array}$ & 266 & 113 & 155 & 186 & 126 & 209 & 125 & 1180 & $1 \%$ & $96 \%$ \\
\hline $\begin{array}{l}\text { Desporto e } \\
\text { lazer }\end{array}$ & 71 & 88 & 96 & 202 & 169 & 164 & 143 & 933 & $1 \%$ & $97 \%$ \\
\hline $\begin{array}{l}\text { Ciência e } \\
\text { tecnologia }\end{array}$ & 59 & 120 & 72 & 76 & 127 & 198 & 35 & 687 & $1 \%$ & $98 \%$ \\
\hline Defesa nacional & 46 & 111 & 94 & 86 & 121 & 124 & 63 & 645 & $1 \%$ & $98 \%$ \\
\hline $\begin{array}{l}\text { Organização } \\
\text { agrária }\end{array}$ & 105 & 100 & 139 & 66 & 74 & 64 & 67 & 615 & $1 \%$ & $99 \%$ \\
\hline Indústria & 98 & 111 & 75 & 88 & 65 & 101 & 44 & 582 & $1 \%$ & $99 \%$ \\
\hline Habitação & 24 & 17 & 38 & 19 & 77 & 93 & 44 & 312 & $0 \%$ & $100 \%$ \\
\hline Urbanismo & 27 & 38 & 39 & 13 & 7 & 32 & 38 & 194 & $0 \%$ & $100 \%$ \\
\hline Saneamento & 13 & 8 & 30 & 31 & 25 & 23 & 10 & 140 & $0 \%$ & $100 \%$ \\
\hline Total & 13595 & 13299 & 15525 & 13203 & 14993 & 17224 & 15380 & 103219 & & \\
\hline
\end{tabular}

Fonte: Pederiva e Rennó (2015)

\section{Apêndice C - Latinobarômetro: principal problema brasileiro}

O Latinobarômetro integra o Globalbarometer Surveys (GBS), que inclui o Eurobarômetro, o Barômetro Árabe, o Afrobarômetro e o Barômetro Asiático. O Latinobarômetro abrange dezoito países da América Latina. Os dados desses estudos anuais são produzidos e divulgados pela Corporación Latinobarómetro, uma entidade privada sem fins lucrativos, sediada na capital chilena, Santiago (LATINOBARÔMETRO, 2010). A partir de 2001, tais dados apresentam credibilidade suficiente para subsidiarem trabalhos acadêmicos. Com apenas uma indicação do principal problema nacional por entrevistado, a cada ano, não ocorrem conflitos de múltiplos picos e transitividade, e a agenda dos problemas observa o espaço unidimensional de função monotônica.

Tabela C - Brasil: principais problemas brasileiros (agenda popular)

\begin{tabular}{|c|c|c|c|c|c|c|c|c|c|c|}
\hline Brasil & 2003 & 2004 & 2005 & 2006 & 2007 & 2008 & 2009 & Total & $\%$ & Soma \% \\
\hline Ociosidade & 472 & 448 & 319 & 244 & 159 & 201 & 222 & 2065 & $25 \%$ & $25 \%$ \\
\hline Saúde & 49 & 84 & 106 & 172 & 187 & 228 & 211 & 1037 & $12 \%$ & $37 \%$ \\
\hline Segurança pública & 109 & 160 & 121 & 81 & 199 & 93 & 73 & 836 & $10 \%$ & $47 \%$ \\
\hline Corrupção & 94 & 34 & 242 & 103 & 229 & 55 & 64 & 821 & $10 \%$ & $56 \%$ \\
\hline Educação & 31 & 61 & 55 & 90 & 90 & 132 & 101 & 560 & $7 \%$ & $63 \%$ \\
\hline
\end{tabular}




\begin{tabular}{|c|c|c|c|c|c|c|c|c|c|c|}
\hline Brasil & 2003 & 2004 & 2005 & 2006 & 2007 & 2008 & 2009 & Total & $\%$ & Soma $\%$ \\
\hline Pobreza & 88 & 124 & 52 & 89 & 88 & 58 & 55 & 554 & $7 \%$ & $70 \%$ \\
\hline Não soube & 10 & 90 & 93 & 86 & 43 & 69 & 73 & 464 & $6 \%$ & $75 \%$ \\
\hline Violência & 0 & 0 & 0 & 0 & 0 & 145 & 161 & 306 & $4 \%$ & $79 \%$ \\
\hline Distribuição de renda & 0 & 0 & 31 & 59 & 66 & 47 & 64 & 267 & $3 \%$ & $82 \%$ \\
\hline Crise política & 0 & 28 & 101 & 47 & 17 & 27 & 17 & 237 & $3 \%$ & $85 \%$ \\
\hline Consumo de droga & 100 & 10 & 5 & 5 & 21 & 14 & 31 & 186 & $2 \%$ & $87 \%$ \\
\hline Inflação & 18 & 76 & 25 & 11 & 5 & 27 & 12 & 174 & $2 \%$ & $89 \%$ \\
\hline Baixo salário & 64 & 33 & 19 & 17 & 13 & 10 & 16 & 172 & $2 \%$ & $91 \%$ \\
\hline Terrorismo & 37 & 8 & 0 & 95 & 1 & 0 & 0 & 141 & $2 \%$ & $93 \%$ \\
\hline Economia & 0 & 0 & 0 & 30 & 28 & 30 & 26 & 114 & $1 \%$ & $94 \%$ \\
\hline Inserção de jovens & 44 & 3 & 3 & 6 & 3 & 3 & 3 & 65 & $1 \%$ & $95 \%$ \\
\hline Instabilidade laboral & 13 & 6 & 2 & 24 & 5 & 0 & 11 & 61 & $1 \%$ & $96 \%$ \\
\hline Narcotráfico & 22 & 5 & 7 & 3 & 4 & 4 & 9 & 54 & $1 \%$ & $96 \%$ \\
\hline Outros & 2 & 14 & 1 & 15 & 3 & 10 & 1 & 46 & $1 \%$ & $97 \%$ \\
\hline Habitação & 12 & 6 & 5 & 4 & 3 & 8 & 6 & 44 & $1 \%$ & $97 \%$ \\
\hline Nenhum & 0 & 3 & 4 & 6 & 2 & 14 & 15 & 44 & $1 \%$ & $98 \%$ \\
\hline Violação de direitos & 12 & 1 & 0 & 2 & 18 & 9 & 0 & 42 & $0 \%$ & $98 \%$ \\
\hline Não respondeu & 0 & 5 & 5 & 12 & 4 & 3 & 4 & 33 & $0 \%$ & $99 \%$ \\
\hline Meio ambiente & 2 & 3 & 5 & 0 & 13 & 2 & 6 & 31 & $0 \%$ & $99 \%$ \\
\hline Discriminação racial & 18 & 0 & 1 & 1 & 2 & 2 & 2 & 26 & $0 \%$ & $99 \%$ \\
\hline Serviço básico & 0 & 0 & 0 & 0 & 1 & 6 & 17 & 24 & $0 \%$ & $100 \%$ \\
\hline Transporte & 3 & 2 & 2 & 1 & 0 & 5 & 3 & 16 & $0 \%$ & $100 \%$ \\
\hline Aquecimento global & 0 & 0 & 0 & 0 & 0 & 2 & 0 & 2 & $0 \%$ & $100 \%$ \\
\hline Fronteiras & 0 & 0 & 0 & 0 & 0 & 0 & 1 & 1 & $0 \%$ & $100 \%$ \\
\hline País vizinho & 0 & 0 & 0 & 1 & 0 & 0 & 0 & 1 & $0 \%$ & $100 \%$ \\
\hline Total & 1200 & 1204 & 1204 & 1204 & 1204 & 1204 & 1204 & 8424 & & \\
\hline
\end{tabular}

Fonte: Pederiva e Rennó (2015)

\section{Apêndice D - Variáveis e estimação dos parâmetros}

Os seis macrotemas em que houve correspondências - trabalho, segurança, saúde, educação, direitos e administração - integram a regressão multivariada linear geral (generalized linear model $-\mathrm{g} / \mathrm{m}$ ) do painel de dados (CAMERON; TRIVEDi, 2010). Como a variável explicada está em percentual, com menores probabilidades de ocorrências nos extremos (0\% e 100\%), a estimação por mínimos quadrados 
produz inferências enganosas. A estimação dos parâmetros observa, portanto, o impacto médio dos públicos nos gastos ("population-averaged" effects), mediante o modelo amplo de estimação (generalized estimating equation - GEE).

O modelo único apresenta a descrição não causal de correspondência entre as agendas de gastos federais, da elite parlamentar no Senado Federal e da população.

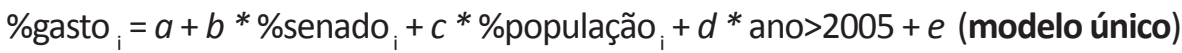

Nesse modelo, as variáveis são identificadas da seguinte maneira:

- $\%_{\text {gasto }_{i}}=$ variável explicada, expressa pelo percentual de gasto anual de cada um dos seis macrotemas (trabalho, segurança, saúde, educação, direitos ou administração).

- Lei (autorizações orçamentárias para gastos previstos no exercício);

- Executado (autorizações orçamentárias utilizadas para gastos no exercício); ou

- Pago (desembolsos ocorridos por conta das autorizações orçamentárias).

- $\quad \% s^{2} n a d o=$ variável explicativa, expressa pelo percentual de registros anuais de cada um dos seis macrotemas (trabalho, segurança, saúde, educação, direitos ou administração).

- \%população = variável explicativa, expressa pelo percentual dos entrevistados que indicaram cada um dos seis macrotemas (trabalho, segurança, saúde, educação, direitos ou administração) como o principal problema nacional.

- $\quad a, b, c, d$ e $e=$ constante $(a)$, deslocada na Tabela 1 para depois dos três parâmetros equivalentes lineares da transformação logística das variáveis $(b, c$ e $d)$, conforme distribuição binomial, sem os problemas de escala na retransformação dos parâmetros, e termo de erro $(e)$, não apresentado na Tabela 1.

O modelo analítico emprega variáveis explicativas do mesmo ano e defasadas em um e dois anos. Essa defasagem permite verificar a consistência intertemporal das agendas, com diferenças temporais de até dois anos, e identificar os efeitos de possíveis variações de temporalidade em cada macrotema (PEDERIVA; RENNó, 2015). Dadas as três situações temporais - (1) dados do mesmo ano e defasados em (2) um ou (3) dois anos -, os resultados assumem a forma de três painéis, um para cada defasagem temporal. Cada painel contém quinze parâmetros, em que a variável \%gasto (na forma de lei, autorizado ou pago) é explicada por (1) \%senado, (2) \%população, (3) ano>2005 e (4) uma constante, acompanhados do respectivo p-value além de (5) quantidade de observações e chi2 da regressão. 
João Henrique Pederiva

Doutor em Américas Comparadas pela Universidade de Brasília, Consultor de Orçamentos do Senado Federal, desde 1997. Professor de graduação e pós-gradução na Universidade de Brasília (UnB). Contato: j.pederiva@yahoo.com.br.

Patrícia Lima Martins Pederiva

Doutora em Educação pela Universidade de Brasília; Pós-Doutorado no Departamiento de Psicologia Evolutiva y Educacióna de la Universidad Autónoma de Madrid, España; Professora do Departamento de Métodos e Técnicas da Faculdade de Educação da Universidade de Brasília (UnB).

Contato: pat.pederiva@gmail.com. 